\title{
Disciplina e capacidade de convivência em sala de aula
}

\section{Discipline and capacity of coexistence in classroom}

Luciane Weber Baia Hees é Doutora em Psicologia da Educação (PUC-SP), Mestre em Educação (UNIMEP). Atualmente exerce a função de Professora Universitária e Professora colaboradora do Mestrado Profissional em Educação do UNASP-EC.

Contato: luciane.hees@ucb.org.br

Raquel Pierini Lopes dos Santos é Mestre em Educação (UNIMEP). Possui pós-graduação em Inclusão Social (UNASP). Atualmente exerce a função de Professora Universitária, Coordenadora de área (PIBID) do curso de Pedagogia do UNASP-EC.

Contato: raquel.lopes@ucb.org.br

Daniele de Castro Rachel é graduanda em Pedagogia no Centro Universitário Adventista de São Paulo (Campus-EC).

Contato: dani.rachel@hotmail.com

Simone Roganti da Silva é graduanda em Pedagogia no Centro Universitário Adventista de São Paulo (Campus-EC.

Contato: siroganti@yahoo.com.br

\section{Resumo}

0 presente artigo tem como objetivo abordar as principais regras existentes dentro de sala de aula que favorecem a convivência entre professor-aluno e aluno-aluno. Para uma adequada relação entre os sujeitos envolvidos no processo ensino-aprendizagem são necessários alguns limites e critérios. A partir de pesquisas científicas, foram abordados nesse estudo elementos que provocam a ausência desses 
valores e princípios em sala de aula, assim como foram elencados alguns pontos que contribuem para melhoria da interação professor-aluno e aluno-aluno, intencionando a qualidade do convívio em sala de aula. Trata-se de uma pesquisa qualitativa de natureza descritiva e que teve como instrumento de coleta de dados uma entrevista com duas professoras do Ensino Fundamental, nível I. Conclui-se que aspectos como a resolução de conflitos, o diálogo, a melhoria das práticas pedagógicas, entre outros, podem fazer do ambiente escolar um lugar adequado para que efetivamente ocorra o aprendizado.

Palavras-chave: Regras; valores éticos e morais; convivência.

\section{Abstract}

The present article aims to address the main rules existing within the classroom that favor the coexistence between teacher-student and student-student. For an adequate lationship between the subjects involved in the teachinglearning process, some limits and criteria re necessary. Based on scientific research, elements that provoke the absence of these values and principles in the classroom were approached in this study, as well as some points that contributed to improving teacher-student and studentstudent interaction, aiming at the quality of the living in the classroom. It is a qualitative research of a descriptive nature and as an instrument of data collection an interview was conducted with two elementary school teachers, level I. We conclude that aspects such as: conflict resolution, dialogue, improvements in practices pedagogical, among others, can make the school environment an appropriate place for learning to take place.

Keywords: Rules; Ethic and Moral Values; Interaction.

\section{Introdução}

Muito tem sido falado sobre regras em sala de aula, bem como a respeito da conduta dos professores e dos alunos para que ocorra efetivamente o processo de ensino-aprendizagem. Numa época em que a liberdade de expressão e os princípios éticos e morais estão sendo confundidos, esses problemas na sociedade acabam afetando a educação escolar. Em um cenário no qual professores 
não estão tendo controle disciplinar nem respeito de seus alunos, e muitas vezes nem estes de seus professores, surgem os que se põem a planejar métodos para implantar regras em sala de aula.

A sala de aula é um espaço em que alunos e professores passam a maior parte de seu dia, e é nesse ambiente que as personalidades se manifestam e o caráter é moldado. A falta de valores e regras gera conflitos e acaba prejudicando as relações de convivência. Segundo Aquino (1996, p. 40), "há muito, os conflitos deixaram de ser um evento esporádico e particular no cotidiano das escolas brasileiras para se tornarem, talvez, um dos maiores obstáculos pedagógicos dos dias atuais".

Este artigo vai abordar duas regras importantes, que são a disciplina e a capacidade de convivência, tendo o relato de experiência como instrumento de coleta de dados, mediante uma entrevista com professoras da educação infantil com oito anos na prática docente. É essencial que o ambiente escolar propicie disciplina e convivência saudável para um bom desenvolvimento na aprendizagem. É importante que o professor conheça a vida de cada aluno e busque métodos para a melhoria da qualidade das relações em sala de aula.

Muito tem sido falado sobre regras em sala de aula, bem como a respeito da conduta dos professores e dos alunos para que ocorra efetivamente o processo de ensino-aprendizagem. Numa época em que a liberdade de expressão e os princípios éticos e morais estão sendo confundidos, esses problemas na sociedade acabam afetando a educação escolar. Em um cenário no qual professores não estão tendo controle disciplinar nem respeito de seus alunos, e muitas vezes nem estes de seus professores, surgem os que se põem a planejar métodos para implantar regras em sala de aula.

A sala de aula é um espaço em que alunos e professores passam a maior parte de seu dia, e é nesse ambiente que as personalidades se manifestam e o caráter é moldado. A falta de valores e regras gera conflitos e acaba prejudicando as relações de convivência. Segundo Aquino (1996, p. 40), "há muito, os conflitos deixaram de ser um evento esporádico e particular no cotidiano das escolas brasileiras para se tornarem, talvez, um dos maiores obstáculos pedagógicos dos dias atuais".

Este artigo vai abordar duas regras importantes, que são a disciplina e a capacidade de convivência, tendo o relato de experiência como instrumento de coleta de dados, mediante uma entrevista com professoras da educação infantil com oito anos 
na prática docente. É essencial que o ambiente escolar propicie disciplina e convivência saudável para um bom desenvolvimento na aprendizagem. É importante que o professor conheça a vida de cada aluno e busque métodos para a melhoria da qualidade das relações em sala de aula.

\section{Disciplina em sala de aula}

Em sua história, as escolas vêm passando por momentos de visível crise no que concerne à disciplina. Estão padecendo tanto as escolas quanto os educadores. Conforme Oliveira (2005, p. 28), a disciplina é compreendida pelo senso comum como a manutenção da ordem e obediência às normas; a primeira significa a sua negação, ou seja, a quebra da ordem. São enormes os desafios de todos os dias, por isso há necessidade de grandes e importantes recursos a fim de se enfrentarem esses gigantes no ambiente educacional.

De acordo com Estrela (1994), o termo disciplina, além de designar um ramo do conhecimento ou matéria de estudo, tem assumido, ao longo do tempo, diferentes significações: punição; dor; instrumento de punição; direção moral; regra de conduta para fazer reinar a ordem numa coletividade; e obediência a essa regra. A autora afirma ainda que esse conceito de disciplina tende normalmente a ser definido pela sua negação ou privação, ou pela desordem proveniente da quebra de regras estabelecidas.

Como explica Vasconcellos (2009), o vocábulo disciplina deriva do latim discapare (captar claramente; disceptare, discutir alguma coisa; discipulus, aluno; disciplina, ensino, doutrina, ciência), sendo usado normalmente para se referir a um domínio limitado do saber e sua representação didática.

De acordo com Vasconcellos (1993), para a maioria dos educadores o conceito de disciplina é entendido como adequação do comportamento do aluno àquilo que o professor deseja. 0 aluno só é considerado bem disciplinado quando se comporta de acordo com o que o professor estabelece; e o indisciplinado é aquele aluno que se caracteriza como desobediente. 0 autor considera que o conceito de disciplina está muito ligado à obediência ese encontra presente todos os dias nas escolas e salas de aula. Além disso, as causas podem ser encontradas em cinco grandes níveis: sociedade, família, escola, professor e aluno. 
No ambiente escolar, a relação pedagógica e a falta de disciplina têm se tornado, nas últimas décadas, expressões usuais, o que representa desafios enormes com os quais os professores precisam conviver em sala de aula.

Segundo Estrela (1994), a relação pedagógica é o contato interpessoal entre os intervenientes de uma situação pedagógica e o resultado desses contatos. Nesse sentido lato, a relação pedagógica abrange todos os intervenientes diretos e indiretos do processo pedagógico: aluno-professor, professor-professor, professor-gestor, professor-pais e alunos-funcionários. A professora $\mathrm{Y}$ do $1^{\circ}$ ano afirma na entrevista que:

\footnotetext{
Um dos desafios do professor em sala de aula sempre foi, e sempre será, manter a disciplina. Quando o professor tem uma aula criativa, dinâmica e clara, ele consegue essa tão desejada disciplina, pois os alunos despertam seu interesse e participam com entusiasmo e vontade de aprender mais.
}

Num sentido restrito, a autora Estrela e a professora entrevistada concordam sobre o que abrange a relação professoraluno e aluno-aluno dentro das situações pedagógicas.

Nas escolas, a ideia de disciplina vem sendo muito discutida há vários anos, mas em toda a história da educação, desde o princípio, ela está presente. Conforme relata Garcia (1999), a disciplina em sala de aula não tem preservado as mesmas características durante os anos; sendo assim, não pode considerar esse fato um fenômeno estático, uma vez que se distingue daquele observado em décadas anteriores. Sobre a falta de disciplina segundo alguns alunos, se não corrigidos, tornam-se indivíduos verdadeiramente agressivos, o que representa um dos motivos pelos quais educadores têm uma grande responsabilidade de aconselhar, dialogar e educar para um futuro melhor e para o exercício de uma verdadeira cidadania. Segundo diz Vasconcelos (2001), ao contrário do que acontecia no passado, o aluno em sala de aula passa a ser o centro de atenção na aprendizagem, no qual o desenvolvimento social e a formação deles passam a ser prioridades do cotidiano educacional. Contudo, houve mudanças na relação professoraluno e na visão escolar.

Nesse ponto, cabe, então, a seguinte reflexão: em que direções, afinal, se deve avançar? Aqui, é destacada a importância de serem ampliados na escola os limites de participação dos alunos em geral. A escola poderia instaurar outro diálogo, ou reinventar o que entende por diálogo. Se o que vem acontecendo nas escolas se destaca muito, a queixa dos professores sobre a 'falta de respeito', 
por exemplo, não significa apenas garantir respeito a esse ou àquele sujeito social. É entendido que ali o respeito precisa antes ser reinventado e aprendido. Conforme fala da professora W, outra docente entrevistada:

\begin{abstract}
Quando falamos de disciplina em sala de aula, existem algumas divergências quanto aos educadores mais tradicionais e os que acreditam que a criança é um ser completo, pensante e comunicativo, cheio de sensações a serem exploradas e curiosidades a serem desvendadas. Quando se acredita em uma disciplina severa, onde todos se sentam o tempo todo e não tem espaço para interações entre as crianças, a escola se torna um lugar ruim de estar, mas se proporcionamos atividades criativas, momentos de diálogos e valorizamos as habilidades e características individuais, tornamos a escola, independente de seus mobiliários ou tecnologias, um lugar prazeroso e o ato de aprender alegre e duradouro. Confesso que não é fácil, pois cada criança é única e alguns nos desafiam em todos os sentidos, tanto com conversas em horas inadequadas, barulhos e brincadeiras, perguntas fora do contexto ou desrespeito, dependendo da região, chegam à escola com tantas frustrações que reproduzem o que vivem. Eu acredito que quando desenvolvemos amor e respeito por eles e por suas histórias de vida, conseguimos enxergar mais do que um aluno indisciplinado, vemos suas potencialidades! Quando tentamos de todas as formas ajudá-los, sem retorno, é imprescindível que a família seja informada sobre as dificuldades encontradas, o que o professor e a escola estão fazendo para ajudá-lo e como a família pode achar soluções (aula de esporte, ajuda de profissionais especializados, criar uma rotina, etc.) para que esta criança melhore seu comportamento e autoconceito. A criança muito quieta ou retraída também precisa de nossa atenção, pois pode estar passando por uma dificuldade e não sabe se expressar ou apenas precisa de mais estímulos para se desenvolver por completo.
\end{abstract}

A escola é um espaço para serem inauguradas outras formas de respeito, talvez na direção sugerida por Sennett (2004), quando fala de respeito como sendo "levar a sério a necessidade percebida em outros". A noção de reconhecimento aí se destaca e precisa ser investigada, significada e praticada dentro das escolas.

0 aspecto mais discutido hoje nas escolas são as consequências da falta de disciplina: professores sofrem com sérios déficits na produtividade da turma e todos dizem que isso dificulta a própria aprendizagem do aluno disciplinado, pois acaba prejudicando a sala como um todo. Isso porque a falta de disciplina, conforme já visto, não somente é manifestada pela desordem, mas também pela falta de atenção e pelo desrespeito ao educador. De acordo com Vasconcellos (2009), o professor deve ter clareza de seu papel e firmeza quanto à sua postura em relação à disciplina. 
Entretanto, sobre as formas de ter disciplina pode ser compreendido que: algumas apontaram a importância da necessidade de autoconhecimento por parte do professor; outras, a importância de um bom relacionamento interpessoal. Mesmo assim, há necessidade da intervenção por parte dos alunos na tomada de decisões sobre o funcionamento da escola. Ainda nesse processo de construção da disciplina escolar é entendido que a família tem um importante papel, seja no sentido de buscar conjuntamente alternativas de superação de problemas, seja porque no lar se encontra, em alguns casos, a origem das primeiras distorções em termos de comportamento.

Visto por um lado positivo, a postura da família colaborará também para a reprodução ou para a transformação de atitudes. É importante e determinante que as regras sejam claras e que seja mantida uma postura de diálogo diante das diferentes situações de disciplina.

\section{Capacidade de convivência}

0 conceito de capacidade de convivência é o "valor que desenvolve no educando a capacidade de viver com a comunidade, na escola, na família, nas igrejas, nos parques, enfim, em todos os lugares onde se concentram pessoas, de modo a garantir uma coexistência interpessoal harmoniosa" (MARTINS, 2005, p. 81).

Vários fatores colaboram para um ambiente saudável em sala de aula, e um deles é a capacidade de convivência. Vivemos em um mundo onde a sociedade "pós-moderna" está inserida em um processo tecnológico de mudanças rápidas e drásticas, e com isso os valores e princípios estão sendo esquecidos e/ou alterados. De acordo com Silva (2007), "o homem, neste início de século, busca uma forma de identificar-se na sociedade em que vive. [...]. Hoje, o homem é um ser com uma identidade híbrida e vive sob o signo da pós-modernidade".

Com as mudanças de culturas e princípios, a escola sofre esse reflexo gerando tensões e conflitos na relação professor-aluno e aluno-aluno, prejudicando, assim, o processo de ensinoaprendizagem. Esses comportamentos causam desconforto para ambos, dificultando a convivência, comportamentos esses representados, de acordo com Fante (2005, p. 200), como "[...] conglomerado de condutas inapropriadas, como falta de cooperação, falta de educação, insolência, desobediência, 
provocação, hostilidade, abuso, impertinência e ameaças". Com essas novas mudanças da sociedade, os alunos vão para a escola com ideias e experiências diferentes, sendo que estas são fruto da relação familiar, relação com a sociedade, comunicação e informações tecnológicas que alteram os princípios morais e éticos adequados para uma boa convivência com todos.

Esses comportamentos atrapalham o planejamento do professor e o impedem de atingir seus objetivos diários, pois este desvia os olhares da aula em si para chamar alunos à atenção e intervir nos desentendimentos ou brincadeiras de alguns, afetando a qualidade do ensino. Segundo Marchesi (2006, p. 79):

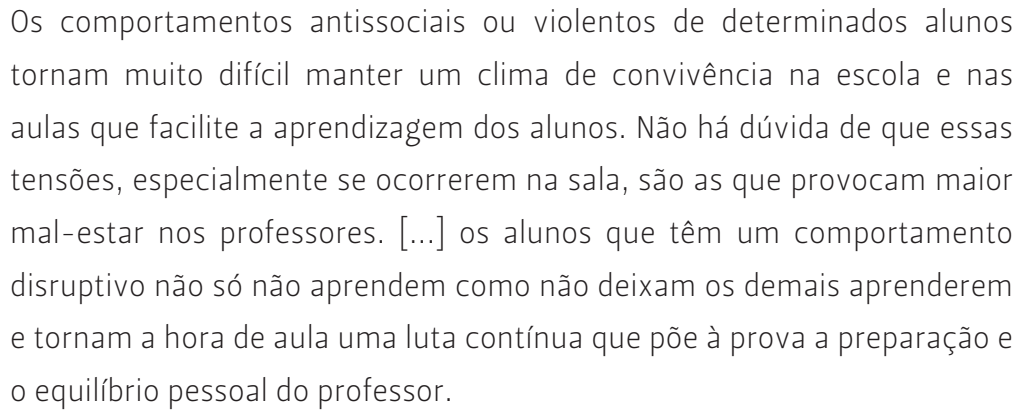

Os alunos mais envolvidos com dificuldades e problemas de relacionamento, desinteresse e falta de concentração enfrentam ainda problemas de relacionamento que provocam danos à qualidade da aprendizagem. Assim, cabe ao professor saber lidar com cada situação e pensar estratégias para solucionar, de forma imediata, tais problemas. Isso muitas vezes tem levado esse professor a uma crise de identidade profissional, gerando estresse, esgotamento, depressão e outros fatores de sofrimento físico, psicológico e espiritual. Algumas orientações de práticas docentes voltadas a regras, cuidados no bem-estar de ambos e uma conduta de diálogo motivam o professor a lidar com essas situações em sala de aula.

Vinha (1999, p.12), com base nos estudos de Piaget, acredita que "os conflitos são ótimas oportunidades para trabalharmos valores e regras". Já Goergen (2007) diz que formar um sujeito moral não depende somente do transmitir, mas também do contribuir para que ele se torne cidadão crítico, político e reflexivo. Dessa forma, compete aos professores terem o desejo de tornar seus alunos sujeitos morais.

Muitas vezes, a convivência entre o professor e os alunos está permeada de atitudes do professor autoritário ou permissivo, gerando um desconforto social. Conforme a fala da professora 
Sila, do $1^{\circ}$ ano,"a convivência fica mais fácil quando o professor entende as fases de cada aluno e tenta compreender as situações e problemas de cada um. Todos têm a capacidade de convivência, desde que cada um respeite a individualidade do seu próximo". A interação social é importante para o desenvolvimento e para se aprender a conviver com a sociedade mostrando condutas e valores. É indispensável que a sala de aula seja um ambiente harmonioso, e com o objetivo de formação de caráter dos alunos e bem-estar de todos. Conforme dizia Paulo Freire (2005, p. 57), "comunicar-se com os alunos é altamente positivo, contribuindo para a formação de cidadãos responsáveis e críticos". 0 trabalho do professor é o de um mediador em qualquer situação em sala de aula.

A capacidade de convivência está relacionada às regras do ambiente. Ao apresentar as regras e ter um diálogo com seus alunos, o educador proporciona melhor desenvolvimento emocional entre eles. Marchesi (2006) fala de quatro estratégias para um ambiente saudável na escola e na convivência em sala de aula. São elas: o diálogo, o desenvolvimento emocional dos alunos, a tutoria e o trabalho em equipe dos professores. Um bom trabalho educativo pode criar sentimentos, valores, boa capacidade de convivência, segurança, amizade e respeito entre ambos.

\section{Considerações finais}

Como parte das reflexões deste artigo, é importante ressaltar que as causas da falta de regras podem ser encontradas em cinco níveis: sociedade, família, escola, professor e aluno. É importante que as normas sejam sempre bem claras e que se mantenha uma postura de diálogo diante das diferentes situações de disciplina e capacidade de convivência. Muitas vezes, é verificada uma posição individualista, uma incapacidade de perceber o todo em relação à sua própria falta de disciplina e capacidade de convivência.

A compreensão da questão da disciplina e capacidade de convivência ainda requer mais discussões e análises sobre o tema, sendo esse um desafio para a escola, a família e a sociedade. Entretanto, conforme também já foi visto, vários fatores ajudam para que seja possível ter em sala de aula um ambiente saudável. Diante de um mundo em constantes mudanças, com um grande desenfreamento da tecnologia em volta, os educadores não podem desanimar. Deve, sim, sempre buscar adaptação à tecnologia, que é parte deste mundo pós-moderno, mas nunca deverá abrir mão de ensinar e resgatar os princípios e valores da sociedade. 


\section{REFERÊNCIAS BIBLIOGRÁFICAS}

AQUINO, J.G.(org.). Indisciplina na escola - alternativas

teóricas e práticas. 4. ed. São Paulo: Summus Editorial, 1996.

ESTRELA, M. T. Relação pedagógica, disciplina e indisciplina na aula. 3. ed. Portugal: Porto, 1994.

FANTE, C. Fenômeno bullying: como prevenir a violência nas escolas e educar para paz. 2. ed. Campinas: Verus, 2005.

FREIRE, P. Pedagogia da Autonomia. Saberes necessários à prática educativa. São Paulo: Editora Paz e Terra, 2005.

GARCIA, J. Indisciplina na escola. Revista Paranaense de Desenvolvimento. Curitiba, n. 95, p. 101-8, jan./abr. 1999.

GOERGEN, P. Educação moral hoje: cenários, perspectivas e perplexidades. Educação e Sociedade, 28(100), 2007, pp. 737-762.

MARCHESI, A. O que será de nós, os maus alunos? Porto Alegre: Artmed, 2006.

MARTINS, V. A prática de valores na escola. Disponível em: <http://www.educacaoonline.pro.br/index.

php?option=com_content\&id=192: - prática - de - valores - na escola\&ltemid=23>. Acesso em: 24.01.2019.

OLIVEIRA, Maria Isete de. Indisciplina escolar: Determinantes, consequências e ações. Brasília: Líber Livro, 2005.

SENNETT, R. Respeito: a formação do caráter em um mundo desigual. Rio de Janeiro: Record, 2004.

SILVA, S. S. da. Identidades Culturais na Pós-modernidade: um estudo da cultura de massa através do grupo Casaca. Disponível em:<http://www.bocc.ubi.pt/pag/silvasergio-salustiano-identidades-culturais.html>. Acesso em: 24.01.2019. 
VASCONCELLOS, C. S. Disciplina: construção da disciplina consciente e interativa em sala de aula e na escola. São Paulo: Libertad, 1993.

VASCONCELOS, M. L. M. C. A pesquisa como princípio pedagógico:discutindo a(in)disciplina na escola contemporânea. In: (In)disciplina, escola e contemporaneidade. Niterói: Intertexto. São Paulo: Mackenzie, 2009. pp.9-26.

VASCONCELOS, Maria L. M. C. A pesquisa como princípio pedagógico: discutindo a(in)disciplina na escola contemporânea. In: (In)disciplina, escola e contemporaneidade. Niterói: Intertexto. São Paulo: Mackenzie, 2001.

VINHA, T. P. Valores Morais em Construção. Revista AMAEEducando, n. ${ }^{\circ}$ 285. Belo Horizonte: Fundação Amae para a Educação e Cultura, ago. 1999, pp. 6-12.

Recebido: 20/09/2018

Revisto: 09/11/2018

Aceito: 01/11/2018 